\title{
COST EFFECTIVE AND EFFICIENT INDUSTRIAL TANK CLEANING PROCESS
}

\author{
Vishwesh Vasadi ${ }^{1}$, Vikas Darasanapalli ${ }^{2}$, Vishal Deodikar ${ }^{3}$, Rupali Kad $^{4}$ \\ ${ }^{1}$ Graduate student, Electronics and Telecommunication, Pimpri Chinchwad College of Engineering, Maharashtra, India. \\ ${ }^{2}$ Graduate student, Electronics and Telecommunication, Pimpri Chinchwad College of Engineering, Maharashtra, India. \\ ${ }^{3}$ Graduate student, Electronics and Telecommunication, Pimpri Chinchwad College of Engineering, Maharashtra, India. \\ ${ }^{4}$ Lecturer, Electronics and Telecommunication, Pimpri Chinchwad College of Engineering, Maharashtra, India
}

\begin{abstract}
The tank cleaning process is one of the major requirements in many industries such as in Pharmaceutical Industries, Fast Moving Consumer Goods Companies (FMCG) and in Paint Industries. The tank cleaning in many small scale industries is still manual and lengthy process. In industries sometimes these tanks are placed in an area where humans cannot go and work, so to avoid this problem we thought of fully automated process of tank cleaning for that we have chosen Programmable Logic Controller (PLC).The $P L C$ is the heart of the system Proposed system provides cost effective and efficient alternate solution to existing system. This system reduces the bulkiness and it is easy to understand (user friendly).It does not require difficult or complex algorithm and coding is also not lengthy. This system stores the water used for the process of tank cleaning instead of throwing away. From conductivity sensor we will come to know the cleanliness of the tank so the ultimate results obtained are reliable and accurate.
\end{abstract}

Keywords: Programmable Logic Controller.

\section{INTRODUCTION}

As per our survey in many Industries, we came to know that in small scale industries automated tank cleaning process is not used. Still they are using conventional method. In this conventional method, man power is used; therefore the reliability of the result (that is cleaning of tank) will depend upon the skills of the individual. To provide a better solution to these small scale Industries we have designed an efficient and cost effective tank cleaning system which can be easily interfaced with the PLC.PLC is the main component of our system. Through our proposed system we have designed a system that would give results same as the systems used in large scale industries with optimum cost. Cost optimization is achieved through simple and self made sensors, but for the lower cost reliability is not compromised. All sensors works on basic principles which gives accurate results

\section{EXISTING SYSTEM}

Except some of the advanced Industries, many Industries still use the conventional method of tank cleaning as shown in figure below. In this method, man power is used; therefore the reliability of the result (that is cleaning of tank) will depend upon the skills of the individual. Therefore we have developed an advantageous way which is completely automated and much more reliable.
$* * *$

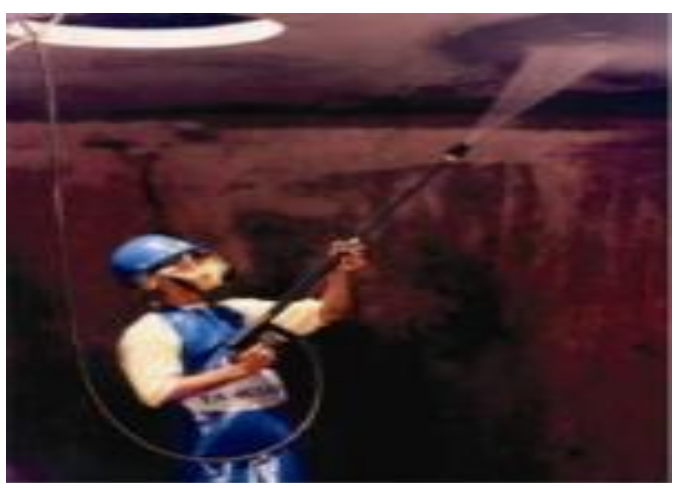

Fig -1: Existing system

\section{BLOCK DIAGRAM}

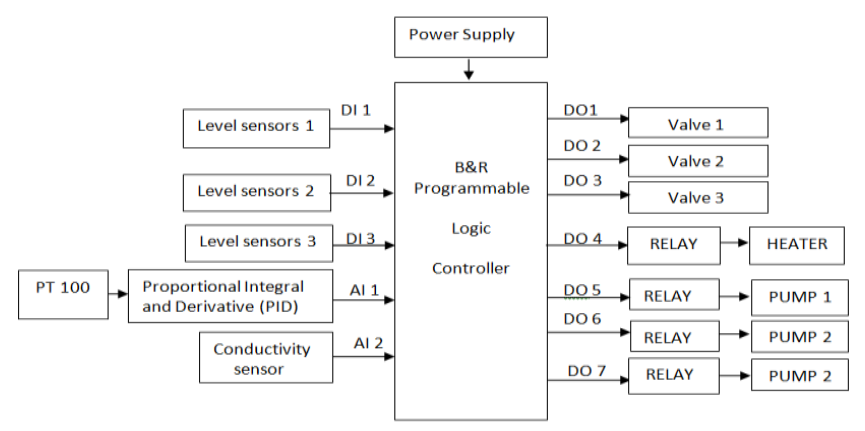

Fig -2: Block diagram 


\subsection{Block Diagram Explanation}

\subsubsection{Temperature Sensor}

We used PT100 as a temperature sensor. A PT100 is a device that gathers data concerning the temperature from a source and using PID it convert into a form that can be understood by an observer. These sensor ranges is from -200 to $660{ }^{\circ} \mathrm{C}$. The required temperature for this system is $40{ }^{\circ} \mathrm{C}$. It works linearly up to $150^{\circ} \mathrm{C}$.

\subsubsection{Level Sensor}

Level sensors detect the level of liquids. The detection of level of liquid is important to know the overflow and underflow of the water and the system will be also be in control. If in case chemicals overflow from the tank then it is harmful and the wastage of chemical occurs. In this system a very simple concept is used for level detection i.e. conductivity of water. The connection will be one positive terminal from battery is kept dip in the tank of which level is to be detected and negative terminal of the battery is connected to ground of PLC and one wire from digital input of PLC is kept at the level of detection .So when the liquid will touch the wire of digital input conduction will takes place and level will detected. The battery for the system used is 24 volt DC and multistand wires.

\subsubsection{Conductivity Sensor}

The conductivity sensor is used to check conductivity of water. The purpose to check the conductivity of water is to check whether the tank is cleaned or not if water is having higher conductivity that means the water is impure and tank is not cleaned if conductivity is less than the water is pure and the tank is cleaned. The model number of sensor is Model ES5 series and the output is directly connected to analog input of PLC. The output is 4-20 milli amperes.

\subsubsection{Heater and Valve}

Heater is used to heat the water. In this system one step is cleaning the tank with hot water so the heater required is operated at 230 volt $\mathrm{AC}$ and of 1000 watts. The valve used is solenoid valve it open and closes when opened the water will flow through it and when closed the water flow is stopped. The solenoid valve used is 24 volt DC operated.

\subsubsection{Pump and Sprinkler}

Pump is used to increase force of water flowing through pipes. This water is then given to sprinkler and the sprinkler will rotate and the water will forcefully hit the wall of the tank. The pump required for this system is 230 volt $\mathrm{AC}$ operated and 18 watt.

\subsubsection{Relay}

Relay is used for switching. To connect heater and pump to PLC relay is required. To output of PLC the relay is connected after that heater same for pump the PLC output to relay then pump. The relay required for the proposed system is 24 volt DC operated; NC is $20 \mathrm{~A} 250$ volt $\mathrm{AC}$ and NO is $20 \mathrm{~A} 250$ volt AC.

\section{SYSTEM DESIGN}

In this system, model consists of three solenoid valves, three level sensors, Conductivity sensor, heater, RTD, three pumps, sprinkler. The valves through which liquids/chemicals will flow into the tanks This valves can be used to control the proportion and flow of each liquid/chemical. Level sensors are used to detect the level of water/chemicals in the tanks. Conductivity sensor used to measure the conductivity of the water. Heater is used to heat the water.PT100 is used to measure the temperature. Pumps to pass the water forcefully through the pipes Sprinkler to clean the tank with water/chemicals

In first step the water will flow from water storage tank to tank A through valve 1 . When water reaches to high level then valve 1 is closed automatically. This water in the tank is then pumped to tank D with high force. This high force of water causes the sprinkler to rotate and tank gets cleaned. Then the output valve is opened.

In second step the cleaning agent stored in reservoir is passed to tank $\mathrm{B}$ through valve 2 . When chemical reaches to high level then valve 2 is closed automatically. This chemical in the tank is then pumped to tank D with high force. This high force of chemical causes the sprinkler to rotate and tank gets cleaned. Then the output valve is opened.

In third step the water will flow from water storage tank to tank $\mathrm{C}$ through valve 3 .When water reaches to high level then valve 3 is closed automatically. Then the water is heated to temperature upto $30-40{ }^{\circ} \mathrm{C}$. This temperature is measured through PT100 after that the heater get turned off. This hot water in the tank is then pumped to tank $\mathrm{D}$ with high force. This high force of water causes the sprinkler to rotate and tank gets cleaned. Then the output valve is opened. Now the conductivity sensor will check the conductivity of water. Through this sensor we are going to check whether the tank is cleaned or not. If there is any impurity present over in the tank $\mathrm{D}$ which are not removable, again the process is repeated from step 2. 


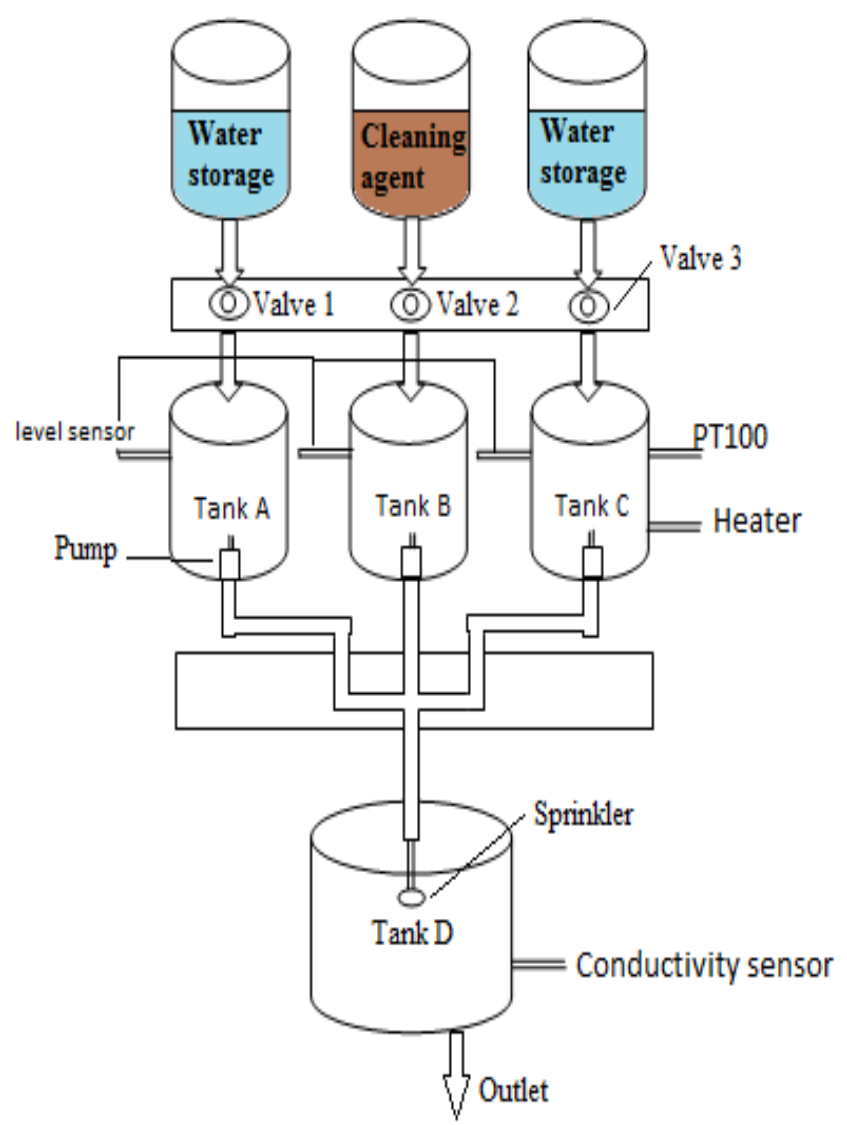

Fig -3: System design

\subsection{System Specification}

Total Number of Input devices $=5$

Total Number of Output devices $=7$

\section{Digital Inputs}

Level sensor $=3$

Pt $100=1$

Conductivity sensor $=1$

\section{Digital Outputs}

Solenoid valves $=3$

Pump $=3$

Heater $=1$

\section{Programming Device}

1GB of RAM

3.66 GHz Processor

Intel Core2Duo Processor

ASBASIC software installed

\section{FLOWCHART}

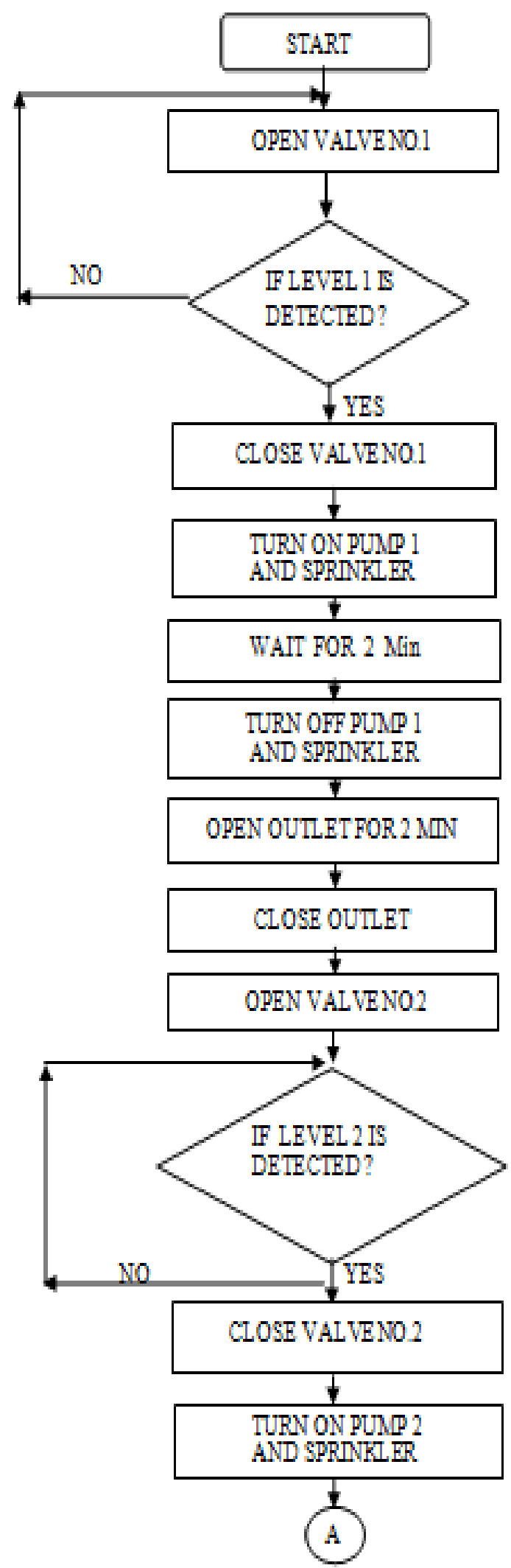




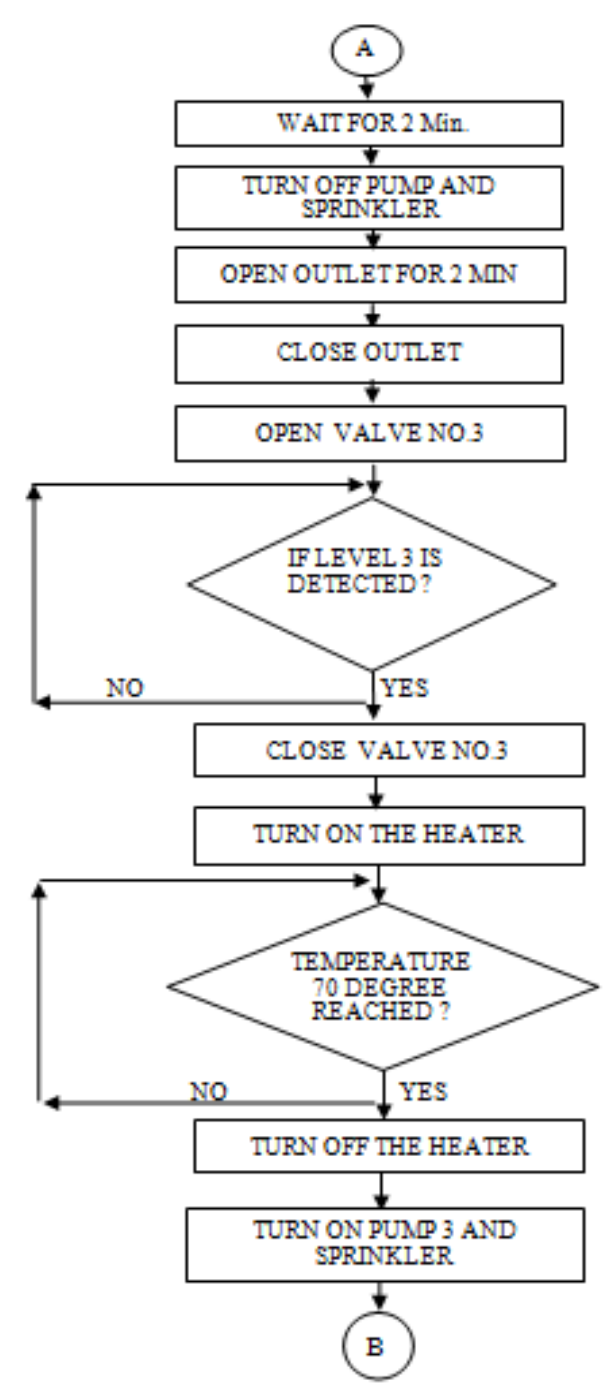

\section{HUMAN MACHINE INTERFACE (HMI)}

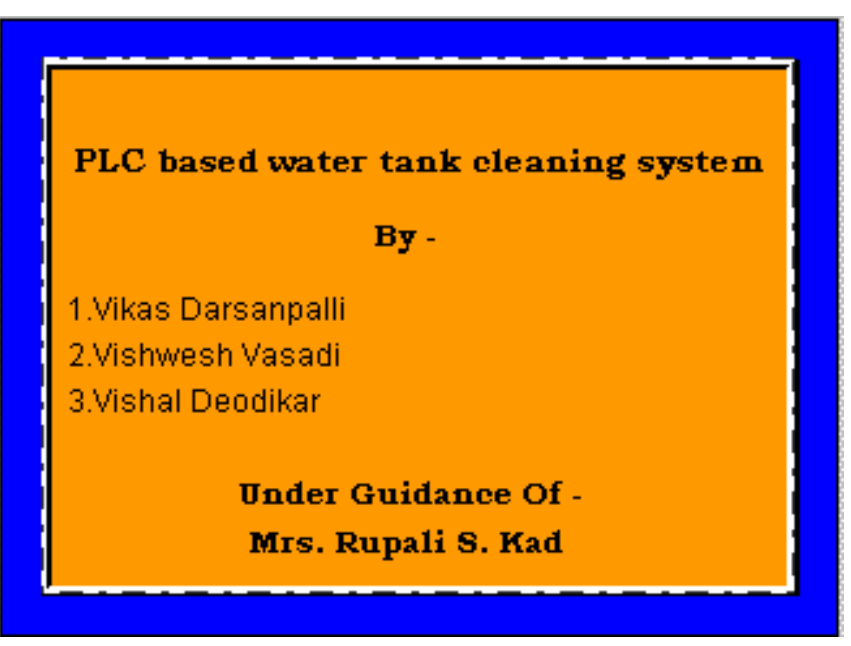

Fig -4: Title page

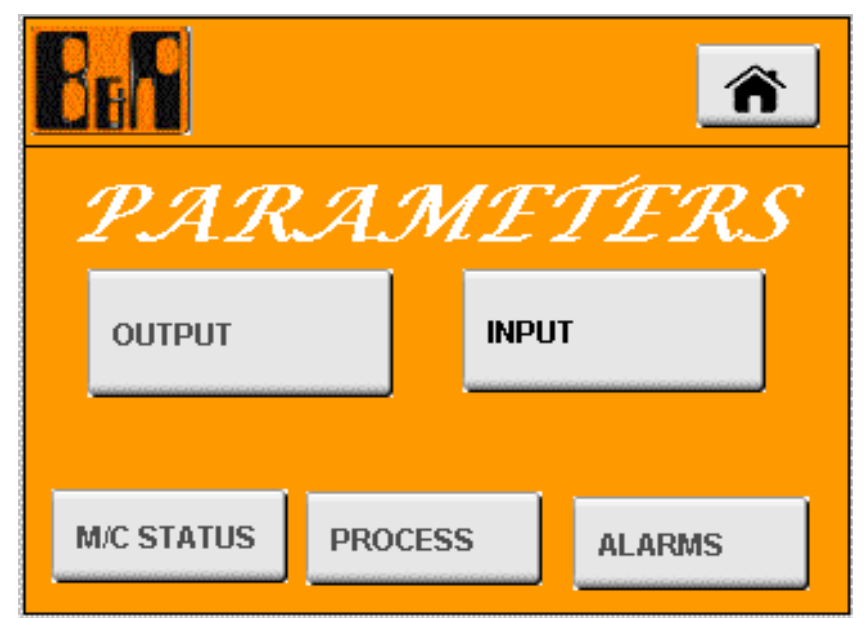

Fig -5: Parameters

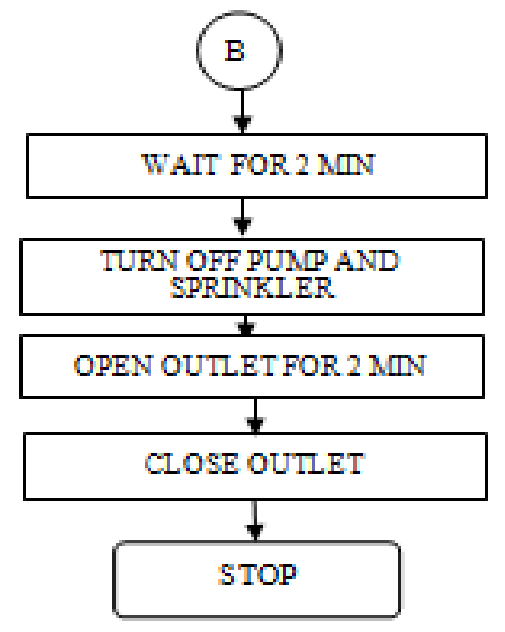

INPUT PARAMETERS

RTD

LEVEL SENSOR

CONDUCTIVITY

SENSOR

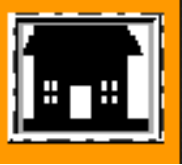

Fig -7: Input parameters 


\section{OUMPUT PARAMETERS}

VALVE

HEATER

SPRINKLER

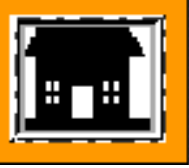

Fig -8: Output parameters

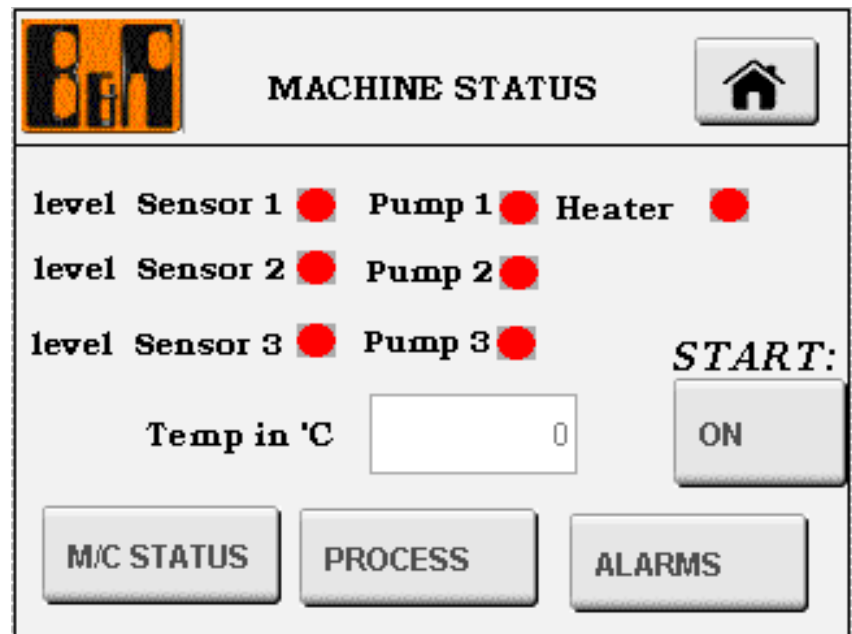

Fig -9: Machine status

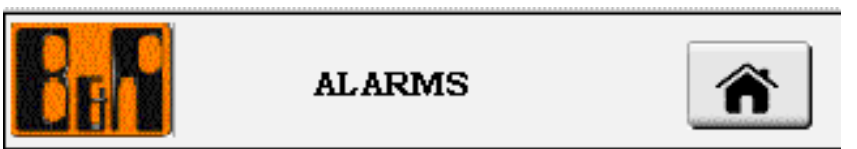

$$
\begin{array}{ll}
012 & \text { AlarmText } \\
\hline 012 & \text { AlarmText } \\
012 & \text { AlarmText } \\
012 & \text { AlarmText } \\
012 & \text { AlarmText }
\end{array}
$$

MIC STATUS
PROCESS

\section{ALARHS}

\section{CONCLUSIONS}

The advantages of our system are $100 \%$ reduced manpower and reduced cost. It increases the speed of the process upto $30 \%$.As it gives required output, the system efficiency is more than $90 \%$. This system can be implemented in small scale industries like vaccine and medicines manufacturing.

\section{REFERENCES}

[1] How to optimize clean-in-place processes in food and beverage operations.-by Benjamin jude and eric lemaire

[2] H. S. Kalsi, electronic Instrumentation Tata McGraw hill Publication

Fig -10: Alarms 